http://jmscr.igmpublication.org/home/

ISSN (e)-2347-176x ISSN (p) 2455-0450

crossref DOI: https://dx.doi.org/10.18535/jmscr/v7i8.53

Journal Of Medical Science And Clinical Research

\title{
Intravenous Dexmedetomidine vs. Intravenous Clonidine to Prolong Bupivacaine Spinal anaesthesia
}

\author{
Authors
}

\section{Dr Sharvari P. Jagadale ${ }^{1^{*}}$, Dr Vidya S.Kelkar ${ }^{2}$}

${ }^{1}$ Senior Resident, Department of Anaesthesia, R.C.S.M. Govt Medical College and CPR Hospital, Kolhapur

${ }^{2}$ Professor, Department of Anaesthesia, B.J. Government Medical College, Pune

*Corresponding Author

Sharvari P. Jagadale

Senior Resident, Department of Anaesthesia, R.C.S.M. Govt Medical College and CPR Hospital, Kolhapur Flat no. 303, Junction 176 Apartment, Near Khanvilkar Petrol Pump, Nagala Park, Kolhapur,

Maharashtra, 416003, India

\begin{abstract}
Aim: Intrathecal adjutants are being used to prolong the action of spinal anesthesia. Most of the studies have been conducted using intrathecal clonidine. This is a randomized clinical trial conducted to compare the effects of intravenous clonidine and dexmedetomidine on $0.5 \%$ bupivacaine in prolonging action of spinal anaesthesia.

Method: A prospective study of 120 patients undergoing lower limb and intra abdominal surgeries were divided into 3 groups: Group A - Received 0.9\% saline infusion 20 minutes after spinal block. All patients received intravenous fluids as needed till the end of surgery. Group B-Received injection clonidine $2 \mathrm{mcg} / \mathrm{kg}$ given as 20 minutes infusion started 20 minutes after spinal block and followed by a $0.9 \%$ saline drip till the end of surgery. Group C - Received an infusion of injection $1 \mathrm{mcg} / \mathrm{kg}$ dexmedetomidine started 20 minutes after the spinal block and infused in 20 minutes, followed by $0.5 \mathrm{mcg} / \mathrm{kg} / \mathrm{h}$ dexmedetomidine drip till the end of surgery. Study was analyzed by Anova test. P value $<0.05$ was considered statistically significant.

Results: Patient demographics were comparable in all groups. Duration of sensory blockade was longer with group $C$ (in minutes) (325.74 \pm 10.59$)$ than group B (270.41 \pm 11.98$)$ and group $A(222.54 \pm 15.03), p$ value 0.001. Duration of motor blockade was longer with group $C(270.97 \pm 6.15)$ than group $B$ $(243.67 \pm 9.22) \&$ group A $(208 \pm 12.83)$, $p$ value (0.001). Duration of analgesia was longer with group $C$ (366.13 \pm 0.19$)$ than group B $(300 \pm 12.65)$ and group $A(252.51 \pm 8.80)$, p value $(0.001)$. Dexmedetomidine has more incidence of bradycardia and hypotension than other two groups but without any major clinical impact.

Conclusion: Intravenous dexmedetomidine and clonidine both prolongs action of spinal anaesthesia and postoperative analgesia than 0.5\% hyperbaric bupivacaine. Dexmedetomidine has longer duration of action than Clonidine due to its alpha 2 receptor selectivity.

Keywords: Clonidine, Dexmedetomidine, Analgesia.
\end{abstract}

\section{Introduction}

Various adjuvants like neostigmine, midazolam, fentanyl and others have been studied to prolong the effect of spinal anaesthesia. ${ }^{1,2}$ Clonidine has been used as an adjuvant drug to enhance the duration and quality of regional anaesthesia. 
Although this alpha 2-adrenoceptor agonist is used by several routes, including oral, intramuscular, intrathecal and intravenously, most studies have been performed injecting clonidine mixed with neuraxial local anaesthetics. ${ }^{3,4}$ Rhee and co-workers were the first clinicians demonstrated that administration of intravenous clonidine prolongs bupivacaine spinal anesthesia. Dexmedetomidine is newer drug in this group and it is used as an adjuvant to regional anaesthesia to improve quality of block a duration of action. Clonidine and Dexmedetomidine, $\alpha-2$ agonist agents are hypothesized to prolong the effect of spinal anaesthesia when given intravenously and more studies are awaited to prove its efficacy ${ }^{5}$.

Hence, this randomized clinical trial was conducted to study the effects of intravenous dexmedetomidine and intravenous clonidine on $0.5 \%$ hyperbaric bupivacaine in prolonging duration of action of spinal anaesthesia.

\section{Methods}

This comparative randomized controlled double blind hospital based study was conducted on 120 patients of ASA grade I \& II, 18 to 60 years of age of both sexes undergoing intra abdominal and lower limb surgeries under spinal anaesthesia after taking approval from institutional ethics committee and written informed consent. Pregnant, chronic medical illness patients are excluded from the study. All patients received diazepam $0.2 \mathrm{mg} / \mathrm{kg}$ orally, the night before surgery. Premedication done with injection ondansetron $0.08 \mathrm{mg} / \mathrm{kg}$. The patients were preloaded with Lactated Ringer's solution 15 $\mathrm{ml} / \mathrm{kg}$. They were monitored with automated noninvasive blood pressure, pulse oximetry and electrocardiogram. 25G Pencil point spinal needles were introduced through L3-L4 interspaces in sitting position using aseptic precautions. $0.3 \mathrm{mg} / \mathrm{kg}$ injection $0.5 \%$ hyperbaric Bupivacaine was given intrathecally and patients were turned supine.

Patients were randomly divided into the following groups: Group A-Received 0.9\%.saline infusion
20 minutes after spinal block. All patients received intravenous fluids as needed till the end of surgery. Group B-Received injection clonidine $2 \mathrm{mcg} / \mathrm{kg}$, given as 20 minutes infusion started 20 minutes after spinal block, and followed by a $0.9 \%$ saline drip till the end of surgery. Group $\mathrm{C}$ - Received an infusion of injection $1 \mathrm{mcg} / \mathrm{kg}$ dexmedetomidine started 20 minutes after the spinal block and infused in 20 minutes, followed by $0.5 \mathrm{mcg} / \mathrm{kg} / \mathrm{h}$ dexmedetomidine drip till the end of surgery. Oxygen (4 L/min) was administered via a venturi mask. Hypotension, defined as a decrease of systolic blood pressure by more than $30 \%$ from baseline or a fall below $90 \mathrm{mmHg}$, was treated with IV fluid and incremental IV doses of mephenteramine $6 \mathrm{mg}$ as required. Bradycardia, defined as heart rate $<50$ beats per minute, was treated with IV atropine $0.3-0.6 \mathrm{mg}$.

The incidence of adverse effects, such as respiratory depression, sedation, bradycardia and hypotension were recorded. Sensory testing was assessed by loss of pinprick sensation to $23 \mathrm{G}$ hypodermic needle and dermatome levels were tested every 30 seconds until the highest level had stabilized by consecutive tests. On achieving sensory blockade level, surgery was allowed. Testing was then conducted every 15 min until the point of two segment regression of the block was observed. Further testing was performed at 30-min intervals until the recovery of $\mathrm{S} 2$ dermatome. The surgeon, patient, and the observing anesthesiologist were blinded to the patient group. Data regarding the time to reach the highest level of sensory blockade from the time of injection, time to S2 level sensory regression, and incidence of side effects were recorded. Sedation was assessed by a modified Ramsay sedation scale. Postoperative Pain assessment done by using VAS score 0 and $10(0=$ no pain, $10=$ most severe pain), initially every $1 \mathrm{~h}$ for $2 \mathrm{~h}$, then every $2 \mathrm{~h}$ for the next $8 \mathrm{~h}$ and then after every $4 \mathrm{~h}$ till $24 \mathrm{hrs}$.\& motor block by modified bromage scale.

\section{Statistical Analysis}

1.The data was managed in Microsoft excel spreadsheet. Demographics are described 
with average, standard deviation, minimum and maximum observation. Demographics and General information like count, average and percentage for various parameters with all permutations and combinations were calculated in Microsoft excels.

2. ANOVA test was applied wherever required. $\mathrm{p}$ value $<0.05$ was considered statistically significant.

\section{Results}

In the present study three groups were comparable with respect to age, weight, height \& duration of surgery (Table No 1). Regression of motor block to Modified Bromage scale 0 was significantly prolonged by dexmedetomidine $270.97 \pm 6.15$ when compared with clonidine $243.67 \pm 9.22$ and control groups $208.00 \pm 12.83$ (minutes) $(\mathrm{P}$ value $=0.0001)$ (Table No.2, Graph no.1). Time for regression to $\mathrm{S} 2$ dermatome was significantly prolonged in group $\mathrm{C}$

$325.74 \pm 10.59$ compared to group B $270.41 \pm$ 11.98 and group A $222.54 \pm 12.03$ ( $\mathrm{P}$ value $=$ 0.0001 ) in the present study (Table No. 2, Graph no 2).
VAS score of $>4$ (mild pain) was regarded as the end point for duration of analgesia \& rescue analgesia was given in the form of injection diclofenac intramuscularly postoperatively. The duration of analgesia in group A was $252.51 \pm$ 8.08 min., $300.46 \pm 12.6 \mathrm{~min}$. in group B and $366.13 \pm 4.60 \mathrm{~min}$. in group C. (p value 0.0001$)$ [Graph No.3]. Sedation was found in all patients in group $\mathrm{B}$ and $\mathrm{C}$ whereas none in group $\mathrm{A}$ in the present study (p value 0.0001) (Table No.3). Mean modified RSS score was between 2-3 in group $\mathrm{B}$ and $\mathrm{C}$. Patients with sedation score greater than three were higher in Group C (20/40) than group B (12/40). Significantly higher number of patients group $C$ [5/40] had bradycardia as compared to group B (3/40) and group A (1/40] (P value $=0.05)$ which was not statistically significant. it didn't produce any major clinical impact in patients.

A higher incidence of hypotension was noted in patients of dexmedetomidine group [5/40] as compared to group B [2/40] and group A [1/40] (P value $=0.09)($ Graph no.4 \&5) in our study but it was not statistically significant.

Table No.1 Showing demographic Data \&duration of surgery

\begin{tabular}{|l|c|c|c|c|}
\hline Demographic Data & Group A & Group B & Group C & P value \\
\hline Age & $33.6 \pm 10.46$ & $35.03 \pm 10.08$ & $34.46 \pm 10.05$ & 0.835 \\
\hline Weight & $53.08 \pm 6.96$ & $53.49 \pm 6.96$ & $53.13 . \pm 7.13$ & 0.962 \\
\hline Height & $161.41 \pm 4.34$ & $160.07 \pm 4.84$ & $160.51 \pm 4.60$ & 0.676 \\
\hline $\begin{array}{l}\text { Duration of surgery } \\
\text { (minutes) }\end{array}$ & $164.88 \pm 5.57$ & $166.9 \pm 5.83$ & $165.1 \pm 4.48$ & 0.835 \\
\hline
\end{tabular}

Table No. 2 Sensory and motor blockade (minutes)

\begin{tabular}{|l|c|c|c|}
\hline & Duration of sensory Blockade & Duration of motor blockade & P value \\
\hline GROUP A & $325.74 \pm 10.59$ & $270.91 \pm 6.15$ & \multirow{2}{*}{0.0001} \\
\cline { 1 - 3 } GROUP B & $270.41 \pm 11.98$ & $243.61 \pm 9.22$ & \\
\hline GROUP C & $222.53 \pm 12.03$ & $208 \pm 12.83$ & \\
\hline
\end{tabular}

Table No.3 Sedation score in patients

\begin{tabular}{|c|c|c|c|}
\hline Ramsay Sedation Score & Group A & Group B & Group C \\
\hline 1 & 40 & 0 & 0 \\
\hline 2 & 0 & 28 & 18 \\
\hline 3 & 0 & 12 & 22 \\
\hline 4 & 0 & 0 & 0 \\
\hline 5 & 0 & 0 & 0 \\
\hline 6 & 0 & 0 & 0 \\
\hline
\end{tabular}


Graph No.1: Motor blockade duration (minutes)

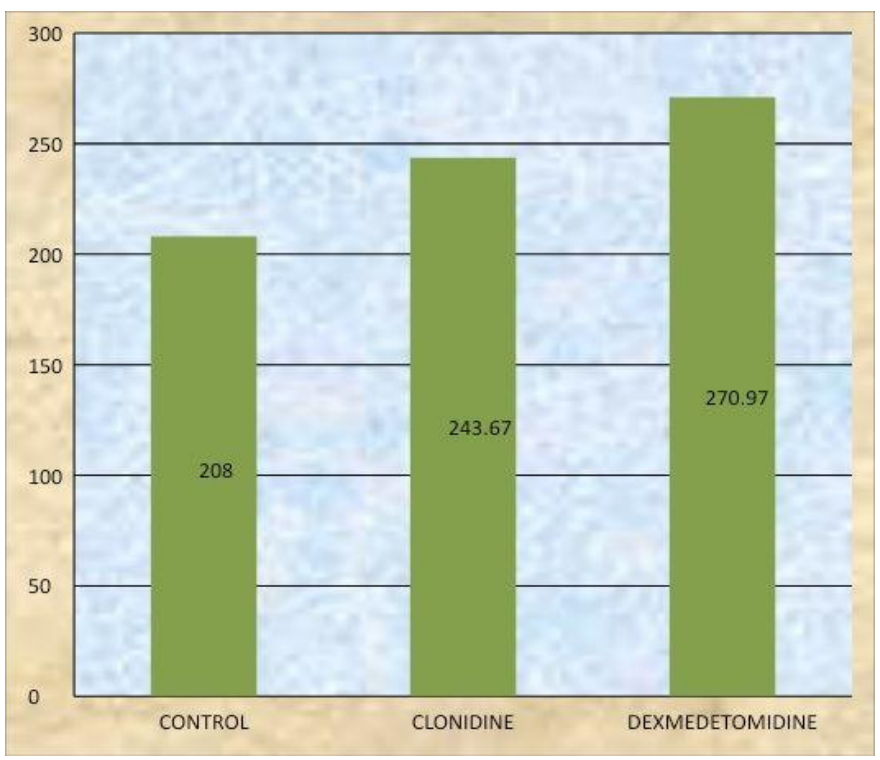

Graph No.2: Duration of Sensory Blockade

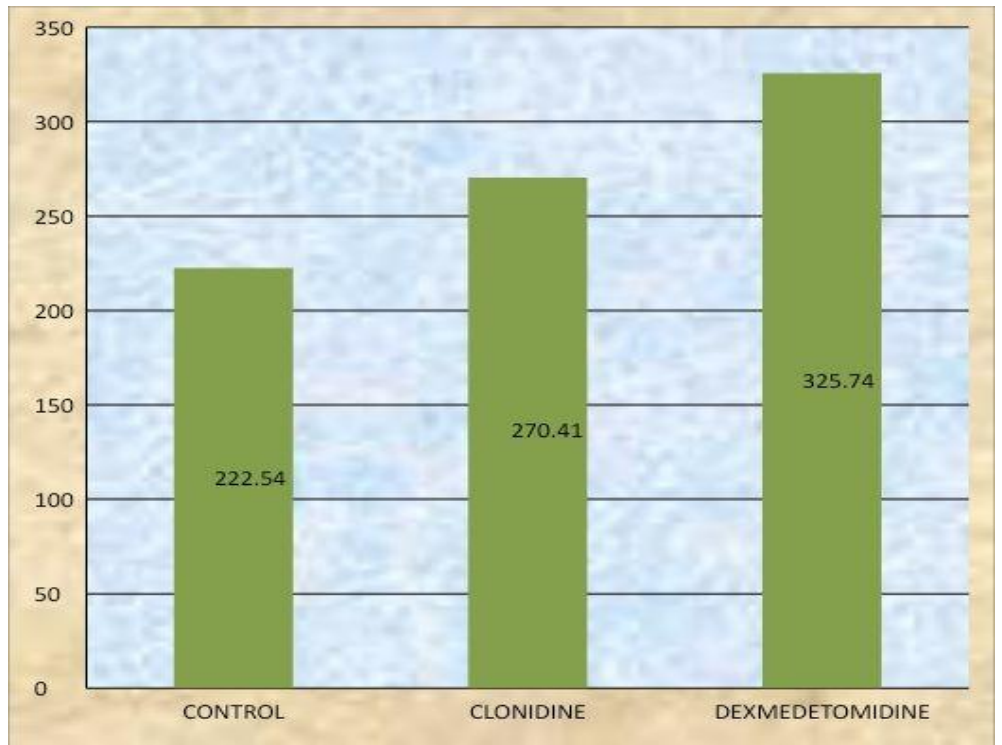

Graph No.3: Duration of analgesia

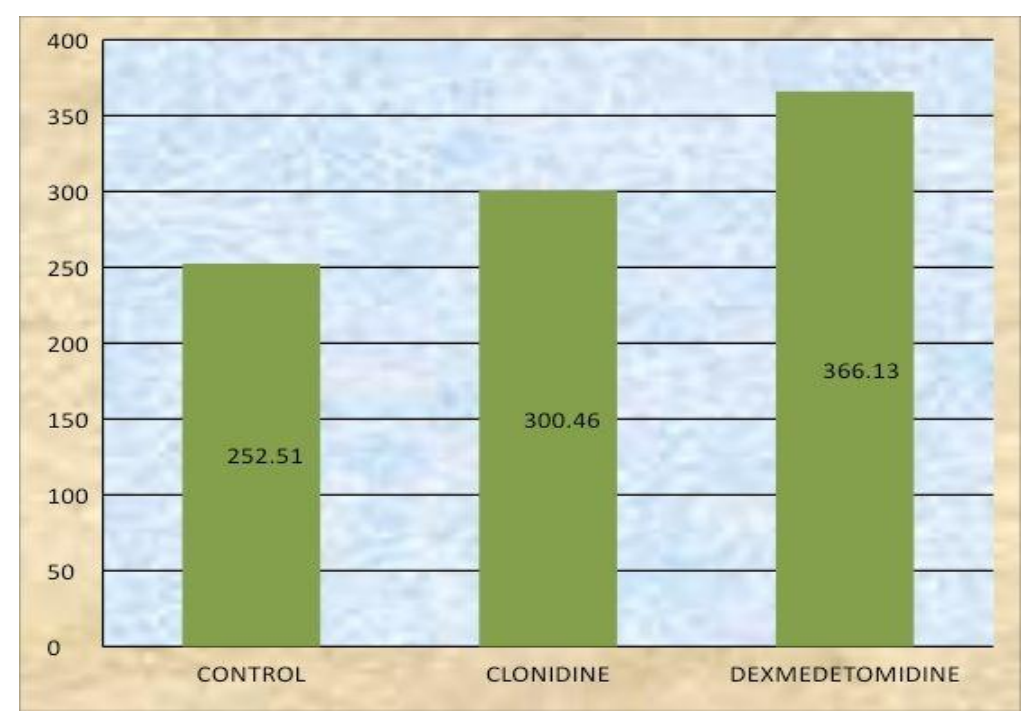




\section{JMSCR Vol||07||Issue||08||Page 304-311||August}

Graph No.4: Comparison of Systolic BloodPressure

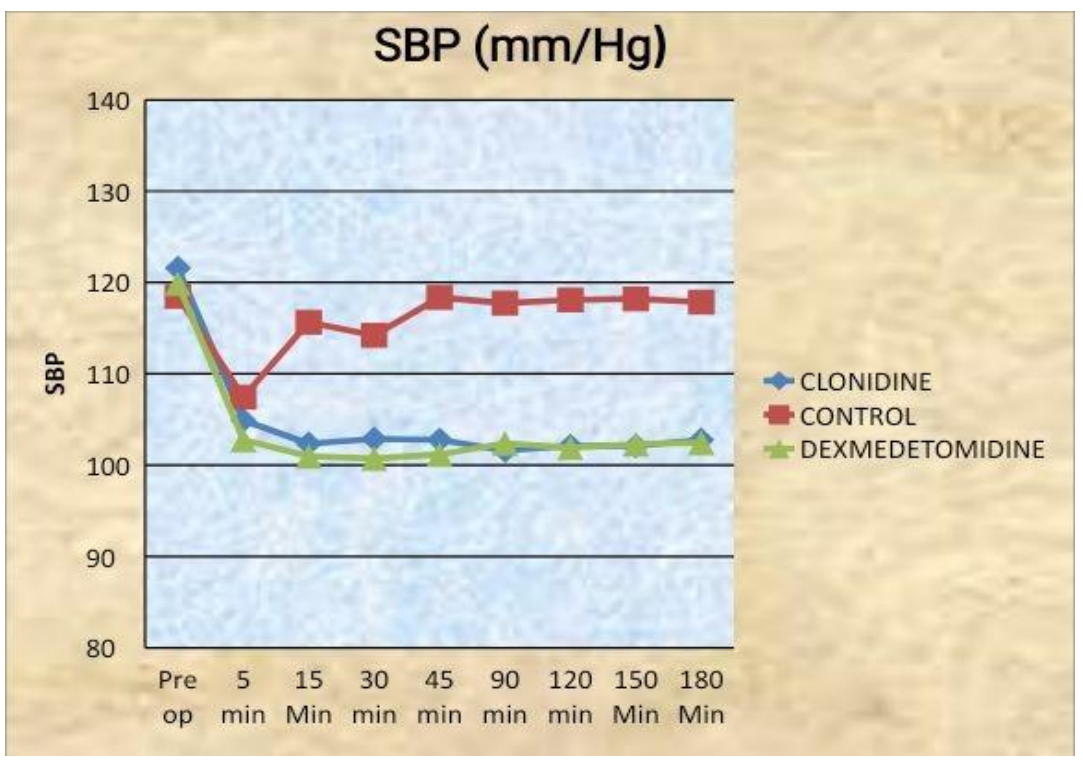

Graph No.5: Comparison of Diastolic BloodPressure

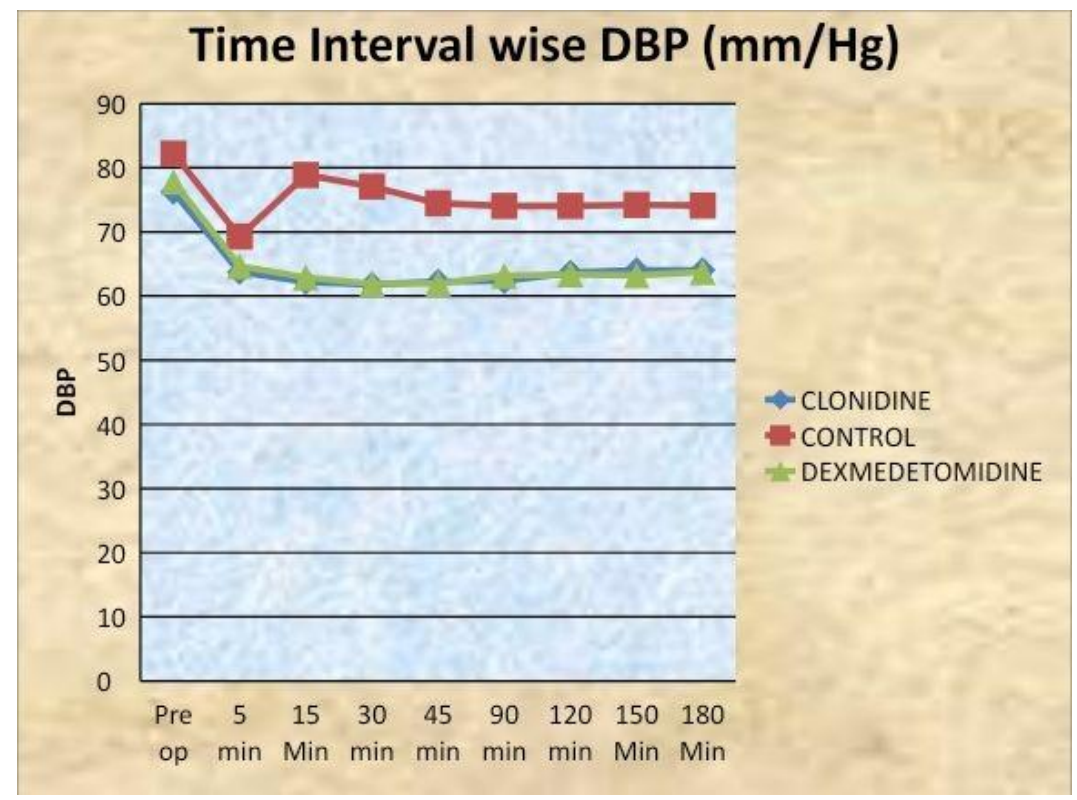

\section{Discussion}

Spinal anaesthesia is one of the most commonly used techniques in anaesthesia. Major disadvantage of the spinal anaesthesia is short duration of action. Different drugs like epinephrine, phenylephrine, adenosine, magnesium sulphate, sodium bicarbonate, neostigmine and alpha2 agonists like clonidine, dexmedetomidine have been used as adjuvants to local anaesthetics to prolong the duration of spinal anaesthesia. ${ }^{17,18,19}$ Among these adjuvants; clonidine an alpha2 agonist is widely used by oral and intrathecal routes as an adjuvant to prolong spinal anaesthesia.

Dexmedetomidine, prototype of this group is also effective adjuvant in spinal anaesthesia. Many studies have been done using these drugs intrathecally and shown to be effective. ${ }^{6,7}$ The aim of our study was to see the effect of clonidine and dexmedetomidine on spinal anaesthesia by intravenous route.

Mechanism of action of dexmedetomidine differs from clonidine as it posses most selective alpha 2adrenoceptor agonist activity especially for the $2 \mathrm{~A}$ subtype of this receptor, which causes it to be a much more sedative and analgesic agent than 
clonidine. Due to this greater selectivity, dexmedetomidine may be more effective than clonidine. In the present study, the effects of intravenous dexmedetomidine on $0.5 \%$ bupivacaine spinal anaesthesia was compared to the effects of intravenous clonidine on $0.5 \%$ bupivacaine spinal anaesthesia in patients posted for elective abdominal and lower limb procedures. duration of sensory and motor block, postoperative analgesia, hemodynamic changes and any other side effects were studied.

Time for regression to S2 dermatome was significantly prolonged in group $\mathrm{C}(325.74 \pm$ 10.59) mins. compared to group B (270.41 \pm 11.98) minutes and group A (222.54 \pm 12.) minutes, $(\mathrm{P}$ value $=0.0001)$ in the present study. Same finding was also reported by Al-Mustafa et al $^{7} 261.5 \pm 34.8$ minutes vs. $165.2 \pm 31.5$ minutes ( $\mathrm{P}$ value $<0.05$ ) in dexmedetomidine and placebo group respectively.

Regression of motor block significantly prolonged in Group $\mathrm{C}$ than group B and (Table no.2). Whizar-Lugo et al ${ }^{8}$ also found that complete resolution of motor blockade was significantly prolonged in dexmedetomidine and clonidine group than placebo. But contrary this result; Reddy et $\mathrm{al}^{10}$ and Kaya et $\mathrm{al}^{9}$ reported no significant difference in prolongation of the duration of motor block in dexmedetomidine group. The duration of motor blockade in dexmedetomidine and clonidine was $150.47 \pm 18.66 \mathrm{~min}$. and in the placebo group it was $140.75 \pm 28.52 \mathrm{~min}$. in a study conducted by Reddy et al. Several studies reported prolonged duration of motor block following use of 1 $\mathrm{mcg} / \mathrm{kg}$ initial bolus dose followed by infusion. However, in a study by Kaya et $\mathrm{al}^{9}$ use of a single dose of $0.5 \mathrm{mcg} / \mathrm{kg}$ of dexmedetomidine did not affect the duration of motor block. The prolongation of motor block observed in our study may be attributed to the continuous infusion following the loading dose. It was observed that effect of clonidine on motor blockade was concentration dependent. Clonidine directly inhibits conduction large myelinated A alpha fibers and $50 \%$ effective concentration measured is 4 fold in small, unmyelinated $\mathrm{C}$ fibers. ${ }^{11}$ This may lead to relatively less prolongation of motor block than sensory block. The same mechanism is attributable to dexmedetomidine.

VAS score of $>4$ (mild pain) was regarded as the end point for duration of analgesia \& rescue analgesia was given in the form of injection diclofenac intramuscularly. The duration of analgesia in group A was $(252.51 \pm 8.08) \mathrm{min}$. $(300.46 \pm 12.6) \mathrm{min}$. in group B and (366.13 \pm 4.60) in group C. (p value 0.0001) Graph no. 1]. There exists a significant difference between duration of postoperative analgesia. In our study, time of first request for analgesic was significantly prolonged in the dexmedetomidine group than clonidine and control groups. This could be attributed to the mechanism of action of dexmedetomidine which differs from clonidine in being eight to ten times more selective to $\alpha 2$ adrenoceptors especially for $\alpha 2 \mathrm{~A}$ and $\alpha 2 \mathrm{C}$ subtype of this receptor.

Reddy et al ${ }^{10}$ also found that dexmedetomidine prolongs duration of analgesia than clonidine and placebo groups. Time for the first dose of analgesic in placebo, clonidine and dexmedetomidine was [140.75] min, [190.93] min and [243.35] min respectively Sedation was found in all patients in group $\mathrm{B}$ and $\mathrm{C}$ whereas none in group A in the present study (p value 0.0001 ).

Mean modified RSS score was between 2-3 in group B and group C. Patients with sedation score greater than three were higher in Group C (20/40) than group B (12/40). Similar result was found by Reddy et al ${ }^{10}$ sedation score greater than 3 and more in dexmedetomidine [64\%] compared to clonidine [24\%] and placebo [12\%]. Activation of presynaptic $\alpha 2-\mathrm{A}$ receptors at locus ceruleus decreases nor epinephrine release and causes sedative and hypnotic effect. patients can be aroused easily and remain cooperative with dexmedetomidine which is different from other sedatives. ${ }^{16}$

A higher incidence of hypotension was noted in patients of dexmedetomidine group [5/40] as 
compared to group B [2/40] and group A [1/40] (P value $=0.09)$ in our study (Table No.14 - Graph No.15). But it was not statistically significant .as we have administered drug slowly over 20 minutes.

Similar results were found by Reddy et $\mathrm{al}^{10}$,the Incidence of hypotension was reported in a higher proportion of patients of dexmedetomidine group [5/25] compared to clonidine[3/25] and placebo group [1/25]; which was statistically not significant. Significantly higher number of patients group $\mathrm{C}$ [5/40] had bradycardia as compared to group B (3/40) and group A (1/40] (P value $=0.05)$ in the present study which was not statistically significant. And it didn't produce any major clinical impact in patients. Low heart rate in clonidine and dexmedetomidine was due to decrease in the sympathetic outflow and decreased levels of catecholamines. ${ }^{12,13,14}$ Similar results were found by Whizar et $\mathrm{al}^{8} \&$ Reddy et al. ${ }^{10}$

Despite providing good sedation, dexmedetomidine and clonidine do not produce significant respiratory depression, providing wide safety margins. In the present study, there was no significant difference in the respiratory rates of both the groups during surgery and postoperative period. There was no significant difference in $\mathrm{SpO}_{2}$ levels between both.

\section{Conclusion}

Inferences drawn from this study are, Duration of sensory, motor blockade and analgesia were significantly prolonged with both intravenous dexmedetomidine and intravenous clonidine. Intravenous dexmedetomidine significantly prolongs duration of sensory, motor blockade and analgesia as compared to Clonidine.

\section{Bibliography}

1. Raj P. Textbook of regional anesthesia. Philadelphia: Churchill Livingstone; 2002.

2. Techanivate A, Urusopone $\mathrm{P}$, Kiatgungwanglia P, Kosawiboonpol R. Intrathecal fentanyl in spinal anesthesia for appendectomy. J Med Assoc Thai.
2004;87(5):525-30.

3. Kaabachi O, Zarghouni A, Ouezini R, Abdelaziz A Ben, Chattaoui O, Kokki H. Clonidine $1 ? ? \mathrm{~g} / \mathrm{kg}$ is a safe and effective adjuvant to plain bupivacaine in spinal anesthesia in adolescents. Anesth Analg. 2007;105(2):516-9.

4. Gecaj-Gashi A, Terziqi H, Pervorfi T, Kryeziu A. Intrathecal clonidine added to small-dose bupivacaine prolongs postoperative analgesia in patients undergoing transurethral surgery. Can Urol Assoc J. 2012;6(1):25-9.

5. Hong JY, Kim WO, Yoon Y, Choi Y, Kim $\mathrm{SH}$, Kil HK. Effects of intravenous dexmedetomidine on low-dose bupivacaine spinal anaesthesia in elderly patients. Acta Anaesthesiol Scand. 2012;56(3):382-7

6. Kanazi GE, Aouad MT, Jabbour-Khoury SI, Al Jazzar MD, Alameddine MM, AlYaman R, et al. Effect of low-dose dexmedetomidine or clonidine on the characteristics of bupivacaine spinal block. Acta Anaesthesiol Scand. 2006;50(2):2227.

7. Al-Ghanem SM, Massad IM, Al-Mustafa MM, Al-Zaben KR, Qudaisat IY, Qatawneh AM, Whizar-lugo V, Gómezramírez IA, Cisneros-corral R, Martínezgallegos N, Médico C, Tijuana BC, et al. Original Article Intravenous Dexmedetomidine vs . Intravenous Clonidine to prolong Bupivacaine Spinal Anesthesia . A Double Blind Study. Anest en México. 2007;19(3):143-6.

8. Kaya FN, Yavascaoglu B, Turker G, Yildirim A, Gurbet A, Mogol EB, et al. Intravenous dexmedetomidine, but not midazolam, prolongs bupivacaine spinal anesthesia. Can J Anesth. 2010;57(1):3945.

9. Reddy VS, Shaik NA, Donthu B, Reddy Sannala VK, Jangam V. Intravenous dexmedetomidine versus clonidine for 
prolongation of bupivacaine spinal anesthesia and analgesia: A randomized double-blind study. J Anaesthesiol Clin Pharmacol. 2013;29(3):342-7.

10. Butterworth JF, Strichartz GR. The alpha 2-adrenergic agonists clonidine and guanfacine produce tonic and phasic block of conduction in rat sciatic nerve fibers. Anesth Analg. 1993;76(2):295-301.

11. Scheinin H, Karhuvaara S, Olkkola KT, Kallio A, Anttila M, Vuorilehto L, et al. Pharmacodynamics and pharmacokinetics of intramuscular dexmedetomidine. Clin Pharmacol Ther. 1992;52(5):537-46.

12. Mason KP, Zurakowski D, Zgleszewski S, Prescilla R, Fontaine PJ, Dinardo JA. Incidence and predictors of hypertension during high-dose dexmedetomidine sedation for pediatric MRI. Paediatr Anaesth. 2010;20(6):516-23.

13. Sudheesh K, Harsoor S. Dexmedetomidine in anaesthesia practice: A wonder drug? Indian J Anaesth. 2011;55(4):323-4.

14. Guo TZ, Jiang JY, Buttermann AE, Maze M. Dexmedetomidine injection into the locus ceruleus produces antinociception. Anesthesiology. 1996;84(4):873-81.

15. Ustün Y, Gündüz M, Erdoğan O, Benlidayi ME. Dexmedetomidine versus midazolam in outpatient third molar surgery. $\mathbf{J}$ oral Maxillofac Surg. 2006;64(9):1353-8.

16. Morrison a. P, Hunter JM, Halpern SH, Banerjee a. Effect of intrathecal magnesium in the presence or absence of local anaesthetic with and without lipophilic opioids: A systematic review and meta-analysis. $\mathrm{Br} \mathrm{J}$ Anaesth. 2013;110(5):702-12.

17. Shadangi BK, Garg R, Pandey R, Das T. Effects of intrathecal midazolam in spinal anaesthesia: a prospective randomised case control study. Singapore Med J. 2011 Jun;52(6):432-5.

18. Boussofara M, Carlès M, Raucoules-Aimé M, Sellam MR, Horn J-L. Effects of intrathecal midazolam on postoperative analgesia when added to a bupivacaineclonidine mixture. Reg Anesth Pain Med. 2006;31(6):501-5. 